\title{
Recall of congruent information in the self-reference task
}

\author{
FRANCIS S. BELLEZZA \\ Ohio University, Athens, Ohio
}

\begin{abstract}
Information descriptive of the self has prior associations with the representation of the self in memory. Therefore, information descriptive of the self should be recalled better than information not descriptive of the self. This is the congruent-information hypothesis. A related hypothesis, the trait-superiority hypothesis, states that trait adjectives are more easily recalled using a self-reference task than using another task. The results of previous research are equivocal with regard to the congruent-information hypothesis and sparse with regard to the trait-superiority hypothesis. College students judged whether trait adjectives and nouns described themselves. Another group judged whether the trait adjectives and nouns described objects in their houses. Results support the congruent-information hypothesis for the self-reference effect, but not the trait-superiority hypothesis.
\end{abstract}

Recall is better when presented information has been processed with respect to the self than when it has been processed in a variety of other ways (Rogers, Kuiper, \& Kirker, 1977). This is the self-reference effect. It is robust and has many implications, including educational ones (e.g., Reeder, McCormick, \& Esselman, 1987). The selfreference effect occurs because the knowledge structure that represents the self in memory forms an elaborate network of nodal concepts and their associations (Bower \& Gilligan, 1979; Kihlstrom \& Cantor, 1984). During learning, a variety of self-information is available in memory that can be related to new information, such as a list of words. Nodes in the self-structure can be activated, and new nodes linked to the existing nodes. When recall is necessary, the well-organized network of self-information is searched for representations of the presented items. Thus use of self-knowledge facilitates the acquisition and retrieval of new information.

Free-recall performance depends on the activation of nodes in an organized memory structure because the nodes act as mental cues for the to-be-remembered information. Furthermore, the nodes must have certain properties to be effective mental cues. This point of view is somewhat different in emphasis than the usual self-schema explanation of the self-reference effect (Kuiper \& Rogers, 1979; Rogers et al., 1977). Its emphasis is on mental cuing. ${ }^{1}$ More detailed discussion can be found in Bellezza (1984, 1986, 1987) and Bellezza and Hoyt (in press).

\footnotetext{
The author would like to thank John Baird for his assistance in collecting and scoring data. All correspondence concerning this article should be sent to F. S. Bellezza, Department of Psychology, Ohio University, Athens, OH 45701-2979.
}

\section{THE CONGRUENT-INFORMATION HYPOTHESIS}

For this discussion, the most important property of a mental cue is associability. Associability represents the ease with which a mental cue can be associated to new information. For example, mental cues generated from the self-knowledge structure may represent personal experiences (Bellezza, 1984, 1986; Bower \& Gilligan, 1979). Remembered experiences can act as associable mental cues because they are high in imagery, familiarity, and meaningfulness and therefore can easily be associated with new information.

In addition, any prior association that exists between the mental cue and the target information will also contribute to the strength of the associative bond. Thus, people should recall information that is related to the knowledge structure that guides processing better than information that is not so related. Some past research showed this to be the case. Congruent information in single sentences (Craik \& Tulving, 1975) and in knowledge structures such as scripts (Bellezza, 1983; Bellezza \& Bower, 1981; Graesser, Woll, Kowalski, \& Smith, 1980) is better recalled than is noncongruent information. Furthermore, several researchers found that descriptive statements, self-descriptive and otherwise, are better recalled than nondescriptive statements (Ganellen \& Carver, 1985; Kuiper \& Rogers, 1979; Lord, 1980; Maki \& McCaul, 1985; Rogers et al., 1977). New information is easily subsumed into a knowledge structure to which it is related. In spite of this theoretical expectation, some researchers did not find superior recall for items judged as selfdescriptive (Kendzierski, 1980; Klein \& Kihlstrom, 1986). In a review of relevant research, Higgins and Bargh (1987) concluded that the great majority of studies found 
that the self-reference effect is independent of the selfdescriptiveness of the target traits. Furthermore, some studies that investigated person stereotypes found that information not congruent with the stereotype is recalled better than is information congruent to it (Hastie \& Kumar, 1979; Srull, 1981). One purpose of the experiment described here is to test the congruent-information hypothesis.

\section{THE TRAIT-SUPERIORITY HYPOTHESIS}

The trait-superiority hypothesis is a variation of the congruent-information hypothesis. Just as information that is descriptive of the self should be better recalled than information that is not descriptive, the self-reference effect may be dependent on other features of materials used. Maki and McCaul (1985) suggested that self-reference processing improves recall for trait words more than for nontrait words because traits represent important components of the self-schema. Traits play a central role in defining the self (Markus, 1977; Wyer \& Srull, 1989) and should be recalled better when related to the self than when related to another knowledge structure in memory. In a selfreference task, subjects have to decide whether trait adjectives, such as loyal, friendly, and rude, describe them. They have probably evaluated themselves in these terms in the past. Therefore, associations between these terms and knowledge of the self probably exist, even if the subject does not consider the trait terms self-descriptive. That is, the greater associability of self-reference cues, as opposed to cues from some other knowledge structure, may explain the trait-superiority effect.

Two experimental conditions were used to test the congruent-information hypothesis and the trait-superiority hypothesis. In the self condition, each subject had to decide whether each presented noun or adjective described $\mathrm{him} /$ herself. In the house condition, the subject decided if the word described some object in his/her house. The use of physical locations as mental cues has a long history in Western thought (Yates, 1966). Previous research found house locations as effective as self-related mental cues (Bellezza, 1986; Bellezza \& Hoyt, in press).

The congruent-information hypothesis suggests that in both the self and house conditions, words judged to be descriptive will be recalled better than words judged not to be descriptive. The trait-superiority hypothesis indicates that subjects in the self condition will recall adjectives relatively better than subjects in the house condition. There are potential confounding factors. First, nouns are generally higher in imagery than are adjectives and are more easily recalled (Maki \& McCaul, 1985; Paivio, 1971). However, because all subjects judged the same words, those in the self condition should recall trait adjectives relatively better. This result is expected from the trait-superiority hypothesis. Second, noncongruent information may be processed to a greater extent than congruent information (Srull, 1981). To equate the degree of processing of items, subjects were instructed to provide a reason for each of their self-descriptive judgments.

\section{METHOD}

\section{Subjects and Materials}

Sixty-eight subjects from introductory psychology courses volunteered to participate for extra course credit. Personality-trait words from Anderson (1968) were selected to represent a range of likableness values (artistic, bright, crude, dependable, fashionable, foolish, helpful, inaccurate, lucky, messy, middleclass, modern, noisy, scientific, showy, silly, unhealthy, versatile, warm, wasteful). Because the orientation tasks involved the self or objects in a house, adjectives were chosen to be meaningful when applied to persons or to objects. Also included in the study list were 20 concrete, familiar nouns (apple, baby, banquet, car, cat, cigar, coffee, garden, hammer, lemon, library, mountain, orchestra, piano, policeman, sea, snake, star, tree, yacht).

\section{Procedure}

The subjects were tested in small groups of 10 to 15 each, randomly assigned to either the house condition or the self condition. Thirty-five subjects participated in the house condition and 33 in the self condition. No subjects were dropped from the experiment.

Each subject in the house condition read a word and then circled "yes" or "no" on a response sheet to indicate whether the target word described an object in his/her house. To try to equate the degree of processing of the words (Srull, 1981), the subjects were instructed to give a reason, in 10 words or less, for each "yes" or "no" response. Each subject in the self condition followed the same procedure except that the "yes" or "no" indicated whether the target word described him/herself. This meant that the nouns had to be interpreted metaphorically. The experimenter paced the subjects through the 40 target words, allowing $40 \mathrm{sec}$ to process each word. No more than 2 adjectives or 2 nouns appeared in sequence in the list.

After a 3-min interpolated task that involved the solution of word anagrams, the subjects were administered a surprise free-recall test that lasted for $\mathbf{1 0} \mathrm{min}$. They had to write down the $\mathbf{4 0}$ target words and the reasons they gave for each word's "yes" or "no" response. The subjects were encouraged to write down target words even if they could not recall the reason associated with a word and to write down any reasons recalled even if they could not recall a corresponding target word.

\section{RESULTS}

\section{Proportion of "Yes" Responses}

Although no predictions were made regarding the proportion of "yes" responses to be made in each condition, a $2 \times 2$ analysis of variance (ANOVA) was performed on the proportion of times a subject indicated that an adjective or noun described him/herself or an object in his/her house. The proportions of "yes" responses are shown in Table 1. The subjects in the house condition gave more "yes" responses than did the subjects in the self condition $\left[F(1,66)=60.94, M S_{\mathrm{e}}=.02, p<.001\right]$. Also, there were more "yes" responses for adjectives than for nouns $\left[F(1,66)=33.90, M S_{\mathrm{e}}=.01, p<.001\right]$. There was no significant interaction between the two factors. The proportions of "yes" responses ranged from

Table 1

Mean Recall and Proportion of "Yes" Responses for Traits and Nouns Given by Subjects in the House and Self Conditions

\begin{tabular}{llll}
\hline & House & \multicolumn{2}{c}{ Self } \\
\hline Traits & $.52(.82)$ & $.42(.63)$ & $.47(.73)$ \\
Nouns & $.50(.71)$ & $.51(.53)$ & $.50(.62)$ \\
& $.51(.77)$ & $.46(.58)$ & \\
\hline
\end{tabular}

Note-The numbers not in parentheses represent the proportion of target words recalled. The numbers in parentheses represent the mean proportion of "yes" responses given in the orienting task. 
.53 for nouns in the self condition to .82 for traits in the house condition.

\section{Testing the Congruent-Information Hypothesis}

The subjects recalled .46 of the trait adjectives judged to be self-descriptive, compared with .34 of the traits judged not to be self-descriptive. This difference was statistically significant $[F(1,32)=7.84, p<.01]$. Also, a difference was observed for the nouns in the self condition, with recall levels of .59 versus .43 , respectively $[F(1,32)=19.01, p<.001]$. But in the house condition, the proportion of descriptive adjectives recalled was .53 , compared with .49 for nondescriptive adjectives. This difference was not statistically significant. Similarly for nouns, the two proportions were .50 and .46 , respectively. This difference also did not reach statistical significance.

\section{Testing the Trait-Superiority Hypothesis}

A $2 \times 2$ ANOVA was performed on the proportions of target words recalled, with the between-subject factor being encoding condition (house vs. self) and the withinsubject factor being word type (adjectives vs. nouns). The proportions of target words recalled are shown in Table 1. There was no significant main effect of encoding condition or word type, but there was a significant encoding condition $\times$ word type interaction $\left[F(1,66)=8.52, M S_{\mathrm{e}}\right.$ $=.01, p<.005]$. Adjectives in the self condition were recalled more poorly than were words in the other three conditions. This result was surprising, because the traitsuperiority hypothesis suggests that traits in the self condition be recalled better, not worse, than traits in the house condition.

\section{DISCUSSION}

\section{The Congruent-Information Hypothesis}

The results of the experiment generally support the congruentinformation hypothesis. In both the self and house conditions, the subjects recalled descriptive adjectives and nouns better than words judged to be nondescriptive. In the house condition, however, the differences in recall were in the correct direction but did not reach statistical significance.

It is not clear why the congruent-information hypothesis should be supported more in the self condition than in the house condition. When an item is judged to be descriptive, then information should exist in the knowledge structure that can act as a mental cue for recall of the item. But what does a nondescriptive, or "no," response mean? When presented a trait, such as "fashionable," a "no" judgment occurs if the subject in the self condition cannot think of anything fashionable about $\mathrm{him} /$ herself. Hence, no mental cue exists for recall of the trait "fashionable." This response can be considered a no-example negative response. A "no" response can also occur if the subject thinks of some aspect of him/herself that is not fashionable. For example, the subject may think of his/her preference for discarded military clothing. So, a mental cue exists for the trait word "fashionable," although the subject made a "no" judgment. This type of response is a counterexample negative response. This distinction is similar to the distinction made by Hastie and Kumar (1979) between neutral and incongruent trait adjectives. More no-example negative (neutral) responses than counterexample negative (incongruent) responses may have occurred in the self condition than in the house condition. This would explain why recall of nondescriptive traits was worse in the self condition than in the house condition.

Because each subject gave a reason for each of his/her "yes" and "no" responses, it was possible to obtain some idea of what each sub- ject was thinking when responding. However, the reasons provided were often difficult to categorize as no-example versus counterexample. For a trait like "fashionable," the reason given in the self condition might be "I am not fashionable," or in the house condition "Our house is not fashionable."

Even if a subject uses some counterexample reasoning, the mental cuing approach suggests generally better recall for "yes" responses than for "no" responses. However, some researchers have predicted equal recall of "yes" and "no" target items based on the organization of the list into "yes" and "no" categories in memory (Klein \& Kihlstrom, 1986). Yet, from the mental-cuing point of view, this explanation is flawed because there are only two category cues in memory, representing the "yes" and "no" categories, and they have too many target items associated with them to be effective. They suffer from cue overload (Watkins, 1979). ${ }^{2}$ In addition, in the present experiment nearly all the words in the house condition were descriptive, so nearly all were in the "yes" category. Therefore, recall should be poorer in the house condition than in the self condition, in which "yes" and "no" responses were more evenly split. Yet recall overall was slightly better in the house condition (.51) than in the self condition (.46). Clearly, dichotomous organization is not the major factor that influences recall performance.

\section{The Trait-Superiority Hypothesis}

The recall data do not support the trait-superiority hypothesis. The subjects recalled trait adjectives more poorly in the self condition than in the house condition. Self-reference processing seems not to enhance the recall of all trait adjectives, as Maki and McCaul (1985) suggested. However, the trait adjectives used were not typical of those used in selfreference experiments. Helpful, fashionable, middleclass, dependable, and inaccurate could be used to describe both physical objects and people. Self-reference may aid the recall of common trait adjectives because people may define commonly used adjectives in terms of selfcharacteristics. On the other hand, the trait adjectives used here are as descriptive of people as they are of physical objects.

Self-reference processing does not always result in optimal recall compared with other types of processing (Bellezza, 1986; Bellezza \& Hoyt, in press). The self condition was less effective for recalling traits than was the house condition. Bellezza and Hoyt (in press) suggested that good recall performance results from associating target information with knowledge structures in memory that represent familiar people, objects, situations, or events. The knowledge structure that represents the self is not special in this regard. Knowledge structures that are representations of familiar things have the prerequisites for generating mental cues that can support free recall. Furthermore, processing information with respect to one's house may be considered self-reference processing, just as processing information with respect to one's friends can be considered self-reference processing (Greenwald, 1982; Greenwald \& Banaji, 1989). This position, of course, assumes that the self plays a broadly defined role in cognitive processing.

All other factors being equal, people recall congruent information better than noncongruent information. Yet the learner may attend to noncongruent information, that is, information not typical of the knowledge structure that guides processing, more closely than to congruent information. For example, Hastie and Kumar (1979) found that information atypical of an activated person stereotype was recalled better than was typical information. Similarly, using a test of immediate recall, Graesser et al. (1980) found that atypical script actions were better recalled than were typical ones. Noncongruent script information may be attended to longer than congruent information and thereby be better remembered (Bellezza, 1983; Bellezza \& Bower, 1981). For the same reasons, processing information noncongruent to the self may take longer than processing information congruent to the self (e.g., Ferguson, Rule, \& Carlson, 1983). In the present experiment, however, the subjects had to process both types of information to the same degree by giving a reason for each decision. This resulted in congruent information being recalled better than noncongruent information.

\section{REFERENCES}

ANDERSON, N. H. (1968). Likeableness ratings of 555 personality-trait words. Journal of Personality \& Social Psychology, 9, 272-279. 
BellezzA, F. S. (1983). Recalling script-based text: The role of selective processing and schematic cues. Bulletin of the Psychonomic Society, 21, 267-270.

BellezzA, F. S. (1984). The self as a mnemonic device: The role of internal cues. Journal of Personality \& Social Psychology, 47, 506-516.

BellezzA, F. S. (1986). Mental cues and verbal reports in learning. In G. H. Bower (Ed.), The psychology of learning and motivation (Vol. 20, pp. 237-273). New York: Academic Press.

BellezZA, F. S. (1987). Mnemonic devices and memory schemas. In M. McDaniel \& M. Pressley (Eds.), Imagery and related mnemonic processes (pp. 34-55). New York: Springer-Verlag.

BellezzA, F. S., \& Bower, G. H. (1981). The representational and processing characteristics of scripts. Bulletin of the Psychonomic Society, 18, 1-4.

BellezzA, F. S., \& Bower, G. H. (1982). Remembering script-based text. Poetics, 11, 1-23.

BellezzA, F. S., \&oyt, S. K. (in press). The self-reference effect and mental cuing. Social Cognition.

BOWER, G. H., \& GilligAN, S. G. (1979). Remembering information related to one's self. Journal of Research in Personality, 13, 420-432.

Craik, F. I. M., Tulving, E. (1975). Depth of processing and the retention of words in episodic memory. Journal of Experimental Psychology: General, 104, 268-294.

Ferguson, T. J., Rule, B. G., \& Carlson, D. (1983). Memory for personally relevant information. Journal of Personality \& Social Psychology, 44, 251-261.

Galambos, J. A., Abelson, R. P., \& Black, J. B. (1986). Knowledge structures. Hillsdale, $\mathrm{NJ}$ : Erlbaum.

Ganellen, R. J., CARver, C. S. (1985). Why does self-reference promote incidental encoding? Journal of Experimental Social Psychology, 21, 284-300.

Graesser, A. C., Woll, S. B., Kowalski, D. J., Smith, D. A. (1980). Memory for typical and atypical actions in scripted activities. Journal of Experimental Psychology: Human Learning \& Memory, 6, 503-515.

Greenwald, A. G. (1982). Is anyone in charge? Personalysis versus the principle of personal unity. In J. Suls (Ed.), Psychological perspectives on the self (pp. 151-181). Hillsdale, NJ: Erlbaum.

Greenwald, A. G., \& BanaJi, M. R. (1989). The self as a memory system: Powerful, but ordinary. Journal of Personality \& Social Psychology, 57, 41-54.

Hastie, R., \& Kumar, P. A. (1979). Person memory: Personality traits as organizing principles in memory for behavior. Journal of Personality \& Social Psychology, 37, 25-38.

Higgins, E. T., BARGH, J. A. (1987). Social cognition and social perception. Annual Review of Psychology, 38, 369-425.

KENDZIERSKI, D. (1980). Self-schemata and scripts: The recall of selfreferent and scriptal information. Personality \& Social Psychology Bulletin, 6, 23-29.

Kinlstrom, J. F., \& Cantor, N. (1984). Mental representations of the self. In L. Berkowitz (Ed.), Advances in experimental social psychology (Vol. 17, pp. 1-47). New York: Academic Press.
KLEIN, S. B., \& Kinlstrom, J. F. (1986). Elaboration, organization, and the self-reference effect in memory. Journal of Experimental Psychology: General, 115, 26-38.

KuiPER, N. A., \& Rogers, T. B. (1979). Encoding of personal information: Self-other differences. Journal of Personality \& Social Psychology, 37, 499-514.

LORD, C. G. (1980). Schemas and images as memory aids: Two modes of processing social information. Journal of Personality \& Social Psychology, 38, 257-269.

MAKI, R. H., \& McCAUL, K. D. (1985). The effects of self-reference versus other reference on the recall of traits and nouns. Bulletin of the Psychonomic Society, 23, 169-172.

MARKUS, H. (1977). Self-schemata and processing information about the self. Journal of Personality \& Social Psychology, 35, 63-78.

Paivio, A. (1971). Imagery and verbal processes. New York: Holt, Rinehart \& Winston.

Reeder, G. D., MCCormick, C. B., \& Esselman, E. D. (1987). Selfreferent processing and recall of prose. Journal of Educational Psychology, 79, 243-248.

Rogers, T. B., KUIPER, N. A., \& KIRKER, W. S. (1977). Self-reference effect and the encoding of personal information. Journal of Personality \& Social Psychology, 35, 677-688.

SRULL, T. (1981). Person memory: Some tests of associative storage and retrieval models. Journal of Experimental Psychology: Human Learning \& Memory, 7, 440-463.

ThORNDYKE, P. W., \& HAYES-Roth, B. (1979). The use of schemata in the acquisition and transfer of knowledge. Cognitive Psychology, 11, 82-106.

WATKINS, M. J. (1979). Engrams as cuegrams and forgetting as cue overload: A cueing approach to the structure of memory. In C. R. Puff (Ed.), Memory organization and structure (pp. 347-372). New York: Academic Press.

WYER, R. S., \& SRULL, T. K. (1989). Memory and cognition in its social context. Hillsdale, NJ: Erlbaum.

YaTES, F. A. (1966). The art of memory. London: Routledge \& Kegan Paul.

\section{NOTES}

1. Thorndyke and Hayes-Roth (1979) proposed a schema theory similar to the mental-cuing approach used here. However, I will use the term knowledge structure instead of schema because several schemabased theories have been proposed that do not incorporate associative processes. I use the term knowledge structure in a manner similar to that of Galambos, Abelson, and Black (1986).

2. Bellezza (1986) discusses why organizational processes that influence learning reflect the use of mental cues.

(Manuscript received January 19, 1992.) 